\title{
TRANSGENESIS TECHNIQUES AND ITS APPLICATION IN POULTRY PRODUCTION
}

\author{
B. OKON, L. A. IBOM AND G. N. NJUME \\ (Received 27 May 2015; Revision Accepted 17 September 2015)
}

\begin{abstract}
The advent of DNA recombinant technology and the possibility of gene transfer between organisms of different species have presented a wide range of possibilities for the improvement of livestock production. This is demonstrated by the recent progress in gene transfer, animal cloning and assisted reproductive techniques in the field of livestock transgenesis. The ability to introduce foreign DNA into the genome of an organism has proven to be one of the most efficient tools in animal breeding and modern biology. Transgenesis is applied in production of therapeutic proteins, improvement of economic traits such as meat quality, disease resistance, feed conversion efficiency; as well as protection of humans from zoonotic diseases. Thus, transgenic technologies may revolutionalize the production of poultry birds with improved meat quality, low fats, low cholesterol as well as disease resistance in addition to production of biopharmaceutical products with efficiencies far greater than any conventional breeding methods.
\end{abstract}

KEYWORDS: Gene transfer, usefulness, poultry production, techniques.

\section{INTRODUCTION}

The provision of food rich in quality and quantity for the increasing human population has over the years been a challenge for biologists and agriculturists. Genetic engineering with DNA recombinant technology has enhanced the creation of new, interesting techniques to improve food production in both quantity and quality to meet up the fast growing population (Pettite, 1998; Jahav and Siddiqui, 2007 and Scott et al., 2010).

The last two decades have witnessed significant progress in understanding of molecular basis of the genetics of growth and development. This knowledge combined with transgenesis in poultry has the potential to enhance current breeding practices for genetic improvement (Pettite, 2000).

Transgenesis is one of the ways of gene constructs which has been introduced into most species of farm animals like cattle, sheep and goats; poultry birds, pigs, rabbits and fish, with varying degree of success (Jahav and Siddiqui, 2007). Also, Pettite (1998) defined transgenesis as the introduction of foreign Deoxyribonucleic acid (DNA) into the genome of an individual in such a way that it is inserted with stability, expressed in phenotype and transferred from generation to generation with Mendelian principles.

Jahav and Siddiqui (2007) reported that gene transfer in poultry has brought about genotypic variations which have enhanced the improvement of traits of economic value. However, the reality of this implies increased usage of transgenic poultry production. Similarly, Scott et al. (2010) reported that poultry birds are widely used for agricultural, biological, medical and research purposes. Thus, Matthew (2008) noted that, the supply of influenza vaccine for the past thirty years has been produced in embryonated chicken eggs. Furthermore, Stern (2005) observed that the chicken embryo has been a model of choice for many developmental biologists due to its accessibility and ease of manipulation in its natural environment in the shell. Consequently, McGrew et al. (2004), Chapman et al. (2005) and Scott and Lois (2005) confirmed the fact that proper introduction of lentiviral vectors in embryos of freshly laid eggs has been efficient in production of transgenic bird.

According to Jahav and Siddiqui (2007), several techniques on how to modify chicken genome exist, but not all of them have been successful in the forming of transgenic poultry. On the other hand, several of these techniques have made considerable progress and are promising for future application. This paper aims at highlighting the techniques and usefulness of poultry transgenesis.

\section{Protocol of transgenesis}

According to Jahav and Siddiqui (2007), the process of transgenesis involves series of steps, namely:

- Selection of genetic character to be transmitted. The gene of the character must be additive or dominant in action.

- Construction of gene transfer vector.

B. Okon, Department of Animal Science, University of Calabar, Calabar, Cross River State, Nigeria.

L. A. Ibom, Department of Animal Science, University of Calabar, Calabar, Cross River State, Nigeria.

G. N. Njume, Department of Animal Science, University of Calabar, Calabar, Cross River State, Nigeria. 
- Transfer of gene to the target cell

- Identification of transgenic by DNA analysis

- Testing gene expression for stability by crossing homozygous transgenic to hemizygous and also transgenic to non-transgenic.

\section{Techniques in poultry transgenesis}

The introduction of exogenous genes to recipient embryo tissues in order to achieve their transfer into germ line has led to the development of a number of techniques (Pettite, 1998; McGrew et al., 2004; Scott and Lais, 2005; Jahav and Siddiqui, 2007). These techniques include:

- Use of vector

- DNA microinjection

- Use of chimeric chicken

- Laser method

The adoption of any of the above techniques depends on method designed to introduce foreign genetic information into the cells that will give rise to germ cells. Most of the developed techniques will produce birds with mosaic transgene insertion in the germ line (i.e. only several cells in the gonad may carry the transgene). Therefore, efficient targeting of the germ cells is essential for successful production of transgenic poultry (Pettite, 1998; McGrew et al., 2004; Jahav and Siddiqui, 2007; Scott et al., 2010). It is only this type of cells that are able to transmit the transgene to the next and subsequent generations. Thus all the techniques in practical terms, involve the germ cells. Poultry transgenesis therefore, centres on modification of mature oocytes, spermatozoa, fertilized eggs and primordial germ cells at any stage of development.

\section{Use of vectors:}

Jahav and Siddiqui (2007) noted that the use of vector involves three methods viz:

- Retroviral-mediated transfer

- Sperm-mediated transfer

- Embryonic stem cell mediated transfer

However, McGrew et al. (2004), Chapman et al. (2005), Scott and Lois (2005) and Scott et al. (2010) reported another method - Lentiviral transgenesis which was reported to be more efficient in production of poultry birds.

\section{Retroviral-medial transfer:}

Goff (1990) reported that retroviruses are useful vectors for eukaryoric cells because they possess specific enzymatic machinery that actively catalyses the integration of viral genome into the DNA of target cells. The author emphasized that once infected, the integrated retroviral DNA, called provirus is permanently carried by the cells in their genome. Two techniques have been proposed with the use of retrovirus vectors for producing transgenic chicken (Jahav and Siddiqui, 2007). The first involves transfection of blastodermal cell using retrovirus vector and their subsequent reimplantation into gamma irradiated recipient embryo. The second technique involves transfection of blastodermal cells by plasmid which carry various retrovirus sequence before re-implantation. Both of these techniques according to Jahav and Siddiqui (2007) lead to high rate of integration.

\section{Lentiviral transgenesis:}

Lentiviral vectors have emerged as a more efficient and versatile technique for the production of transgenic birds in a variety of poultry species (McGrew et al., 2004; Chapman et al., 2005; and Scott and Lois, 2005). These authors noted that transgenesis carried out by lentiviruses are permanently integrated into the genome of infected cells and inherited by all their daughter cells. Lois et al. (2002) pointed out that lentiviruses have the ability to infect non-dividing cells and can thus be used to generate transgenic birds with high germline transmission rate and robust gene expression in appropriate tissues. The use of lentiviral vectors allow for a range of manipulations, the primary advantage being over expression of gene of interest to increase the production of desired proteins in birds or their eggs (Ivarie, 2003).

\section{Sperm-mediated gene transfer:}

Sperm mediated gene transfer involves the use of sperm as vectors for gene transfer into chickens (Naito et al., 1994; Jahav and Siddiqui, 2007). These authors explained that, in this technique, sperms are coincubated with exogenous genes. This is then transferred by artificial insemination (Al) to the females. The exogenous DNA is found in the fertilized cell episomally.

\section{Embryonic stem cell (ESC) transfer:}

Pettite (2000) and Jahav and Siddiqui (2007) explained that, this method involves using embryonic stem cells as vectors for carrying foreign DNA to recipients. This is possible because of the ability of the embryonic stem cells to differentiate in vitro to form embryoid bodies, undergo spontaneous or chemically induced differentiation. Thus, when injected into a blastocyst is capable of producing all somatic cell types as well as germ line (Pettite, 2000).

\section{DNA microinjection}

In this technique, the foreign DNA is directly injected into the pronucleus of the newly fertilized eggs (Pettite, 2000). The success of this technique however depends on the development of a complete ex vitro system from fertilization to hatch, which would yield numerous hatching to screen for gene integration.

On the other hand, Rowlett (1998) explained that DNA microinjection can be done in three stages, namely:

Stage 1: Newly fertilized eggs surrounded with a capsule of albumen are removed from the magnum, DNA expression vectors are then injected into the cytoplasm of the germinal disc of the ovum before culturing for about 18-24 hours in synthetic oviductal fluid without a shell. 
Stage 2: The egg is transferred to an egg shell which is them completely sealed with no simulation air space.

Stage 3: The embryo is then transferred to a larger shell with an upper space for the remaining period of incubation.

\section{Use of chimeric chicken}

Jahav and Siddiqui (2007) noted that this technique involves two approaches, namely:

- Blastodermal cell transfer

- $\quad$ Primordial germ cell (PGC) transfer

\section{Blastodermal cell transfer:}

In this technique the blastodermal cells are transfected with suitable gene sequence and then injected into the embryo (Pettite, 2000; Jahav and Siddiqui, 2007). This results in development of chimeric chickens which possess both transfected and nontransfected cells. Stable transfection enables the blastodrmal cell to enter the germ line of chimeric chicken which is passed on to the progeny (Brazolot et al., 1991; Fraser et al., 1993). The blastodermal cells are pluripotent and can thus be transmitted from one embryo to another. This property makes transfection of the cell easy.

\section{Primordal Germ cell (PGC) transfer:}

Keefer (2004) reported that this technique involves obtaining primordial germ cells that give rise to germline from the embryo. These cells are then cultured in such a way that they become relatively undifferentiated. They are then transfected with construct DNA designed to allow for homologous recombination. Cells with correct recombination are then selected and expanded in vitro. These cells are then returned to an embryo where they integrate and become part of the cellular make up of the recipient. This gives rise to individuals known as chimeras which at sexual maturity possess germ cells derived from the transgenic donor cells. Breeding of these individuals gives rise to transgenic offspring (Vick et al., 1993; Pettite, 2000; Jahav and Siddiqui, 2007).

\section{Laser method:}

This technique was described by Pettite (1997), Jahav and Siddiqui (2007) as follows: DNA to be introduced into cell is dissolved in the culture medium surrounding the cells. Minute holes are made in the cell membrane by brief pulses with finely focused laser, this allows uptake of DNA by the cell. The holes in the cells are repaired within a fraction of seconds while the DNA is integrated into the cell. However, the efficiency of stable transfection depends on the concentration of DNA in the culture medium.

\section{Application of transgenesis in poultry production}

Reports by several authors (Eduardo et al., 2007; McKay, 2008 and Scott et al., 2010) have it that major applications of poultry transgenesis are production of the therapeutic proteins, improvement of economic traits such as meat quality, disease resistance, feed conversion efficiency and protection of humans from zoonotic diseases.

\section{Production of therapeutic proteins}

Chicken is an important alternative as animal bioreactors, with a number of distinct advantages (Ivarie, 2006; Haudebine, 2009 and Scott et al., 2010). Firstly, chicken eggs are extremely rich sources of proteins and unlike other bioreactors, example milk, eggs content are naturally sterile. Secondly, transgenic chicken requires less time to mature (21 days to hatch; $5-6$ months to attain sexual maturity) compared to livestock such as goats, sheep and cattle. Thus the use of transgenic chicken would reduce significantly, the cost and duration of the developmental process. Thirdly, infrastructure to generate large numbers of eggs at low cost is already available and eggs are also used extensively for production of vaccines, hence, good techniques exist for the extraction of biopharmaceuticals from chicken eggs (Scott et al., 2010).

Scott et al. (2010) reported that some world renown pharmaceutical companies are involved in production of therapeutic proteins through poultry transgenesis (See Table 1 below):

Table 1: Some world pharmaceutical companies involved in production of therapeutic proteins through poultry transgenesis

\begin{tabular}{cll}
\hline S/N & Name of company & References \\
\hline 1 & Viragen & Lillico et al. (2007) \\
2 & Origen Therapeutics & Vande Lavoir et al. (2006a) \\
3 & Avi Genics & Rapp et al. (2003) \\
\hline
\end{tabular}

Source: Scott et al. (2010).

\section{Improvement of economic traits}

McKay (2008) reported that poultry transgenesis has led to identification of alleles that increase flock productivity (for example through feed conversion and disease resistance), which remains a major goal of the poultry industry.
Scott et al. (2010) stated that transgenesis in poultry has enabled the identification of candidate gene for specific traits and greater precision in trait selection, such that once identified; desirable alleles are bred into new poultry strains. The authors observed further, that transgenic techniques not only enable the close study of the genetic pathways that govern traits of interest, but 
also enables the direct introduction of described alleles in the germ line of transgenic birds.

\section{Disease Resistance}

Clark and Whitelaw (2002) reported that the potential application of poultry transgenesis to protect flock from infectious diseases by using RNA interference (RNAi) techniques has aroused great interest in the poultry industry. These authors observed that by expressing short interference RNAs (SiRNAs) target genes from a particular virus for degradation, transgenic birds could be engineered to become genetically resistant to that virus.

\section{Protection of Humans from Zoonotic Diseases}

Poultry species serve as reservoirs for zoonotic diseases such as influenza; hence, the strategy of using RNAi could be useful to control the spread of infectious diseases from birds to humans (Chen et al., 2002). In addition, Getlin et al. (2002) observed that delivery of SiRNAs against viral genes prevent viral infection in cultured cells. This principle however, require further proof through experiments in birds before further application, both to improve poultry meat and to protect humans from zoonotic diseases.

\section{CONCLUSION}

Transgenesis in poultry has enabled the identification of candidate gene for specific traits and greater precision in trait selection. This is such that desirable alleles are bred into new poultry strains, once identified. Transgenic techniques provide a powerful tool for further improvement of genetic stock in two ways. Firstly, it allows close study of the genetic pathways that govern traits of interest. Secondly, it enables the direct introduction of desirable alleles in the germ line of transgenic birds. Transgenic technology may revolutionize the production of genetically improved birds having good meat quality; low fat, and cholesterol as well as disease resistance, with efficiencies far greater than any conventional breeding techniques. Consequently, it is proper to predict that a prudent use of these techniques in poultry production has the potential to yield in the nearest future major innovations that will improve health and standard of living.

\section{REFERENCES}

Brazolot, C, L., Pettite, J. N. Etches, R. J. and Gibbins, A. M., 1991. Efficient transfection of chicken cells by lipofection, and introduction of transfected blastodennal cells into the embryo. Molecular Reproduction Development 30:304-312.

Chapman, S. C., Lawson, A., Macarthur, W. C., Wiesse, R. J., Loechel, R. K, Burgos, M, Trinidad, M., Wakefleld, J. K., Ramabhadran, R., Mauch, T. J., Schoenwolf, G. C., 2005. Ubifiquous GFP expression in transgenic chickens using a lentiviral vector. Development 132: 935-940.
Chen, J., Stem, P., Scott, B. B., Lois, C,. 2008. Genetic strategy to prevent influenza virus infections in animals. Journal of Infectious Diseases 197 (1): S25-S28.

Clark, J. and Whitelaw, B., 2003. A future for transgenic livestock. Nature Resource Genetics 4: 825833.

Eduardo, O. M., Aurea, M. O., Mauricio, M. F. and Rumpf, R., 2007. Animal Transgenesis: State of the art and applications. Journal Applied Genetics 48(1) pp 47-61.

Fraser, R. A., Carsience, S., Clark, M. E., Etches, R. J., and Gibbins, A. M., 1993. Efficient incorporation of transfected blastodermal cells into chemieric chicken embryos. International Journal Development Biology 37:381-385.

Getlin, L, Karelsky, S., Andino, R., 2002. Short interfering RNA confers inrracellular antiviral immunity in human cells. Nature 418:430-438.

Goff, S. P., 1990. Integration of retroviral DNA into the genome of the infected cell. Cancer Cells 2:172178.

Haudebine, I. M., 2009. Production of pharmaceutical proteins by transgenic animals. Comprehensive Immunological Microbiology of Infectious Disease 32:107-121.

Ivarie, R., 2003. Avian transgenesis: Progress towards the promise. Trends Biotechnology 21:99-101.

Ivarie, R., 2006. Competitive bioreactor hens on the horizon. Trends Biotechnology 24:99-101.

Jahav, N, V. and Siddiqui, M. F., 2007. Hand Book of Poultry and Management. $2^{\text {nd }}$ Edition, Jay Pee Brothers Medical Publishers $(P)$ Limited. New Delhi.

Keefer, C. L., 2004. Production of bioproducts through the use of transgenic animal model. Animal Reproduction Science 82-83; 5-12,

Lillico, S. G., Shearman, A., McGrew, J. M., Robertson, C. D., Smith, J., Halsam, C, Bernard, P., Radcliff; P. A., Motrophanus, R. A. Elliot, E. A., Sang, H. M., 2007. Oviduct specific expression of two therapeutic proteins in transgenic hens. Proceedings National Academic Science USA 104:17711778.

Lois, C., Hong, E. J., Peaser, S., Brown, E. and Baltimore, D., 2002. Germline transmission and tissuespecific expression of transgenesis delivered by lentiviral vectors. Science 295:868-867.

Matthew, J. T., 2008. Egg-based production of influenza vaccine, 30 years of commercial experience. The Bridge 36:17-24. 
McGrew, J. M., Shearman, A., Ellard, F. M., Lillico, S. G., Gilholdey, H, J., Kingsman, A. J., Mitrophanous, K.

A. and Sang, H., 2004. Efficient production of germ line transgenic chickens using lentiviral vectors. EMBO reports 7:728-733.

McKay, J. C., 2008. The genetics of modern commercial poultry. Proceedings of the $23^{\text {rd }}$ World's Poultry Congress, Brisbane, Australia CD-ROM.

Naito, M., Sasaki, E., Ohtaki, M. and Sakurai 1994. Introduction of exogenous DNA into somatic and germ cells of chickens by microinjection into germinal disc of fertilized ova. Molecular Reproduction Development 37: 167-171.

Pettite, J. N., 1998. Avian pluripotent stem cells. Mechanical Development 121:1159-1168.

Pettite, J. N., 2000. Current technologies for transgenic poultry. Development of Poultry, North Carolina State University Raleigh, NC, 27603.

Rapp, J. C., Harvey, A, J., Speksnijder, G., Hu, W.,

Ivarie, R., 2003. Biologically active human interferon alpha-2b produced in the egg white of transgenic hens. Transgenic Research 12:569575.

Rowlett, K. A., 1998. Embryo growth and development in culture. In S. G. Tullet, ed. Avian Incubation. Butterworth - Heinemann, Boston, M. A. Pages 107-124

Scott, B. B. and Lois, C., 2005. Generation of tissuespecific transgenic birds with lentiviral vectors. Proceedings National Academic Science USA 102:16443-16447.

Scott, B. B., Tarciso, A. V., Shuyin, S. and Lois, C., 2010. Application of Avian Transgenesis. ILAR Journal 51(4): 353-361.

Stern, C. D., 2005. The chick, a great model system becomes even greater. Development Cell 8:917.

Vande Lavoir, M. C., Diamond, J. H., Leighton, P. A., Mather-Love, C., Heyer, B. S., Bradhsaw, R., Kewrchner, A., Hoi, L. T., Gessaro, T. M., Swanberg, S.

E., Delany, M. E., Etches, R. J., 2006a. Germline transmission of genetically modified primordial germ cells. Nature 441;766-769.

Vick, L., Liu, Y. and Simkiss, K., 1993. Transgenic birds from transformed primordial germ cells. Proceedings Research Society, London. B. 251:179-182. 